\title{
Effects of Appalachian Culture and Pregnancy Status on Pain- Related Fear
}

\author{
Cecelia Irene Nelson \\ West Virginia University, cil0004@mix.wvu.edu
}

Follow this and additional works at: https://researchrepository.wvu.edu/etd

Part of the Clinical Psychology Commons, Health Psychology Commons, and the Pain Management Commons

\section{Recommended Citation}

Nelson, Cecelia Irene, "Effects of Appalachian Culture and Pregnancy Status on Pain-Related Fear" (2020). Graduate Theses, Dissertations, and Problem Reports. 7651.

https://researchrepository.wvu.edu/etd/7651

This Thesis is protected by copyright and/or related rights. It has been brought to you by the The Research Repository @ WVU with permission from the rights-holder(s). You are free to use this Thesis in any way that is permitted by the copyright and related rights legislation that applies to your use. For other uses you must obtain permission from the rights-holder(s) directly, unless additional rights are indicated by a Creative Commons license in the record and/ or on the work itself. This Thesis has been accepted for inclusion in WVU Graduate Theses, Dissertations, and Problem Reports collection by an authorized administrator of The Research Repository @ WVU. For more information, please contact researchrepository@mail.wvu.edu. 
Effects of Appalachian Culture and Pregnancy Status on Pain-Related Fear

Cecelia I. Nelson, B.A.

\author{
Thesis submitted \\ to the Eberly College of Arts and Sciences \\ at West Virginia University \\ in partial fulfillment of the requirements for the degree of \\ Master of Science in \\ Psychology
}

Daniel W. McNeil, PhD, Chair

Shari A. Steinman, $\mathrm{PhD}$

Richard T. Gross, PhD

Bryan Weaver, DDS, MD

Department of Psychology

Morgantown, West Virginia

2019

Keywords: pain-related fear, pregnancy, Appalachia, culture

Copyright 2020 Cecelia Nelson 


\section{Abstract \\ Effects of Appalachian Culture and Pregnancy Status on Pain-Related Fear}

\section{Cecelia I. Nelson}

Fear of pain during pregnancy is an understudied phenomenon with important implications for prenatal and postpartum functioning. The aim of the current study was to understand the role of pregnancy and culture on pain-related fear in Appalachia. Archival datasets, and a new sample of women recruited via Amazon's Mechanical Turk, were sources of data. Participants completed the Fear of Pain Questionnaire-9 and responded to demographic questions in order to ascertain whether they were pregnant at the time of the study as well as the number and nature of prior pregnancies. In support of hypotheses, results indicated that pregnant women reported lower fear of pain compared to non-pregnant women, and that, among women, living in Appalachia was associated with lower fear of pain relative to living elsewhere in the USA. It was hypothesized that being pregnant and living in Appalachia would interact, yielding the lowest reports of painrelated fear among those women, relative to other groups, however, this interaction was not significant. Additionally, it was hypothesized that nulliparous women would experience higher rates of fear of pain than parous or multiparous women; this effect was significant in fear of severe pain. The results of this study contribute to knowledge about the role of Appalachian culture and perinatal changes in the experience and expression of pain. These findings also provide direction for future research into the mechanisms that protect women from fear of pain, potentially related to how they may be applied to populations outside of Appalachia or nonpregnant women. 


\section{Acknowledgements}

Thank you to Dr. Daniel McNeil for his mentorship of this project, and my professional journey in general. Thank you to my parents, Kevin and Laura Lentz for their endless support of my scholarly pursuits. Thank you to my husband, Luke Nelson, for supporting me during my hours of writing, and for constantly motivating me. Thank you to the women who participated in this study for your time and your contribution to science.

Funding for this study was provided by the Eberly College of Arts and Sciences Department of Psychology Thesis and Dissertation fund. Additional funding was provided by grants supporting Cecelia I. Nelson (T32-GM132494, R01-DE014889) and the thesis chair, Daniel W. McNeil, PhD (R21-DE026540, R01-DE014889). 


\section{Table of Contents}

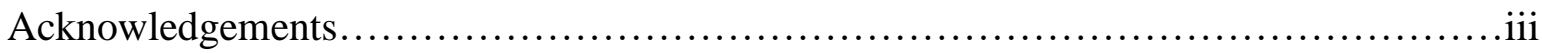

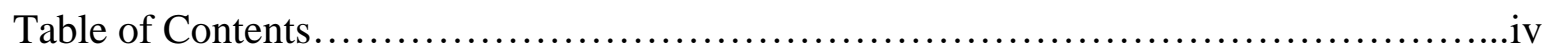

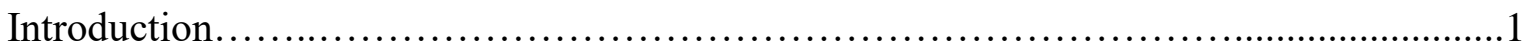

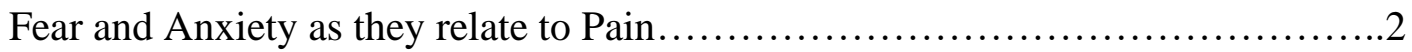

Perinatal Anxiety and Fear................................................. 4

Fear of Pain and Fear of Labor...............................................5

Appalachian Culture and Pain.............................................. 8

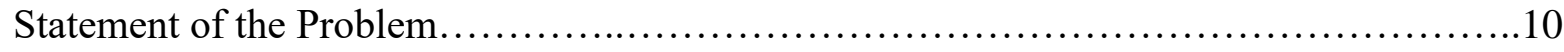

Hypotheses.....................................................................

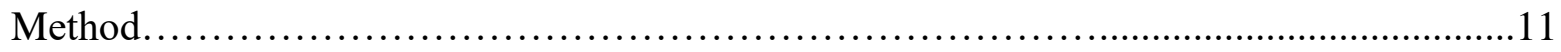

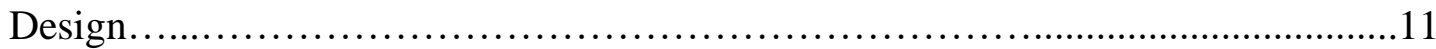

Sample Size Determination..................................................11

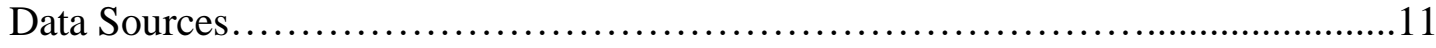

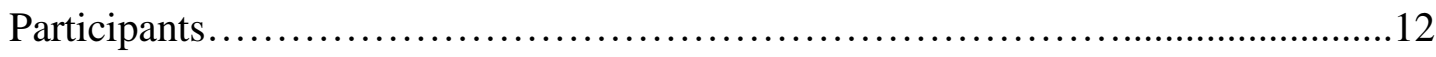

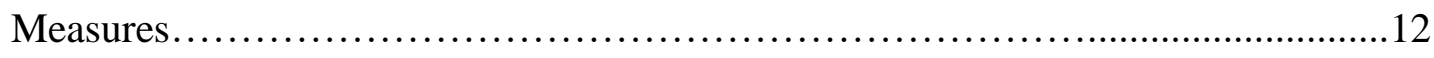

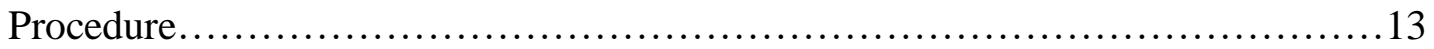

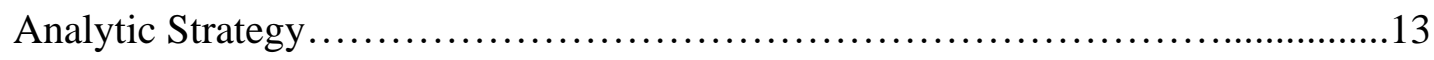

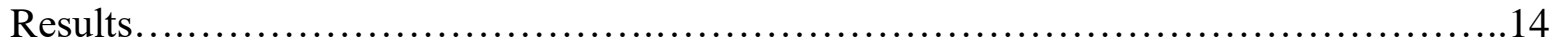

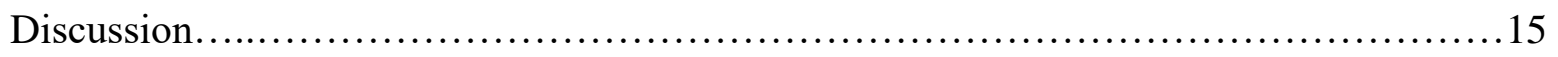

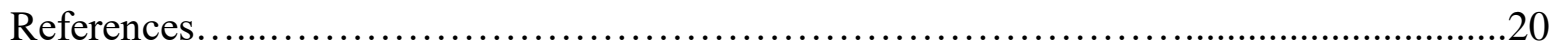

Figure 1: Differences in Fear of Pain: Pregnancy X Region................................31 


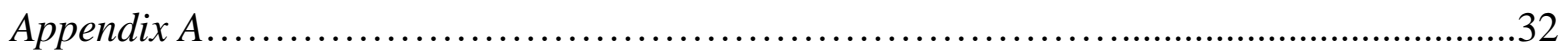

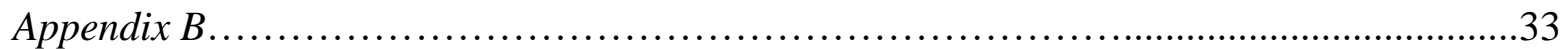

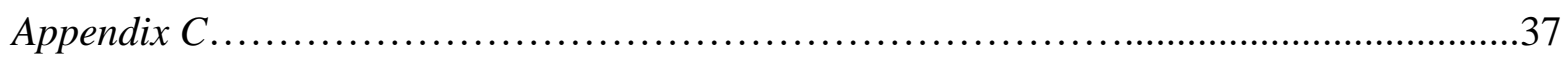


Effects of Appalachian Culture and Pregnancy Status on Anxiety and Fear associated with Pain Many physiological and psychological changes occur during pregnancy have an impact on the health of the mother and the developing child. Psychological factors such as perinatal anxiety, fear of pain, and fear of childbirth/labor are subject to change during pregnancy due to hormonal and lifestyle changes.

While changes in fear and anxiety manifest during pregnancy, many other factors also contribute to the presence and intensity of these states in the perinatal period. For example, cultural differences affect fear and anxiety, and an individual's experience in the healthcare system, during pregnancy and at other times in women's lives. As one example, during pregnancy, some cultural groups have greater utilization of healthcare than others. For example, Wilson, Kratzke, and Hoxmeier (2012) found that rural Appalachians reported that their community was affected by problems associated with affording healthcare, transportation to the nearest provider, low education, low income, and lack of health insurance. Minimal prior experience with healthcare providers or the discomfort of various prenatal procedures may contribute to the development of anxiety or fear surrounding interactions with a healthcare professional during prenatal, postnatal, and pediatric care. A qualitative study that examined adolescent mothers in Appalachia found that a misunderstanding of health insurance or lack of education about pregnancy and contraception presented a unique barrier to perinatal treatment (Dalton \& Miller, 2016). Additionally, communication with healthcare practitioners was described as confusing and misleading (Dalton \& Miller, 2016). Therefore, Appalachians may be more vulnerable to perinatal anxiety or fear due to already existing apprehensions about the medical community, low access to healthcare, and negative or confusing experiences with healthcare providers. 
Various cultures may also hold different beliefs about pregnancy and childbirth that could affect reactions to or utilization of healthcare during the perinatal period and birth. For example, culture may influence the degree to which women view institutionalized birth, or birth in a hospital, as opposed to one's home, as preferable or acceptable (Withers, Kharazmi, \& Lim, 2018). It is also possible that cultural differences have a protective role, such that life experiences with pain or hardship, or differences in self-efficacy, may positively impact emotions related to pain. These cultural differences, however, have not yet been investigated in an Appalachian sample. In order to investigate the nature of fear of pain during pregnancy, and how Appalachian culture shapes this fear, it is important to understand the connections between fear and anxiety, and what is already known about how these variables impact women's lives.

\section{Fear and Anxiety as they relate to Pain}

Fear and anxiety have pivotal roles in the development and maintenance of pain (Asmundson \& Taylor, 1996; Gross \& Collins, 1981; Linton \& Shaw, 2011; McNeil \& Rainwater, 1998; Swinkels-Meewisse, Roelofs, Oostendorp, Verbeek, \& Vlaeyen, 2006). Fear is a present-oriented aversive emotional state that is associated with preparing the body for escape or avoidance in response to certain threatening stimuli (McNeil, Arias, \& Randall, 2017). Fear is unhelpful when it is misplaced, as it can lead to avoidance of various non-threatening activities (e.g., a person who fears heights avoids travelling by plane may drive vast distances to avoid flying). With regard to the relation between fear and pain, the fear-avoidance model of chronic pain (Asmundson, Norton \& Vlaeyen, 2004; Leeuw et. al, 2007; Vlaeyen, Crombez, \& Linton, 2016) explains that individuals who are experiencing pain begin to avoid physical activities due to fear of re-injury or increased pain (Demmelmaier, Björk, Dufour, Nordgren, \& Opava, 2018; Fritz, George, \& Delitto, 2001; Pfingsten, et al., 2001; Vlaeyen, Kole-Snijders, Rotteveel, 
Ruesink, \& Heuts, 1995). This fear of pain or injury is not only distressing, but also plays a significant role in the development of disability (Vlaeyen \& Linton, 2012).

Another line of research investigates fear and pain as competing states, rather than as fear affecting pain or vice versa. Vowles, McNeil, Sorrell, and Lawrence (2006) presented individuals with a fear-inducing stimulus (i.e., inhalation of carbon dioxide gas), as well as a pain-inducing stimulus (i.e., pressure pain stimulation) and examined verbal reports of fear and time to escape. Results suggested that whichever stimulus (fearful or painful) was considered to be most distressing or salient to the individual held the individual's attention and prompted escape behavior. If carbon dioxide concentration was low (i.e., low fear), more pain was reported, and if high (i.e., high fear) less pain was indicated. This investigation indicates that fear and pain may actually be competing for salience, rather than acting synergistically.

Anxiety can be differentiated from fear and is described as, "a future-oriented affective state" (Leeuw et. al, 2007, p. 78), and in its adaptive form, it serves an anticipatory function. Anxiety is adaptive when it prepares an individual to experience a future event. In its maladaptive form, however, anxiety is associated with excessive worry and rumination. Anxiety is typically considered to be more cognitive in nature when compared to fear, which is associated with greater behavioral changes and physiological arousal (e.g., avoidance, increased heart rate, increased respiration; McNeil \& Rainwater, 1998). As for its relation with pain, in some studies, anxiety has been shown to increase sensitivity to pain and experience of pain (Gerrits, van Marwijk, van Oppen, van der Horst, \& Penninx, 2015; Ploghaus, 2001; Rhudy \& Meagher, 2000). For example, Klages, Ulusoy, Kianifard, and Wehrbein (2004) found that individuals with high dental anxiety both expected and experienced more pain during their dental procedure than those with low dental anxiety. Alternatively, other studies have shown that anxiety (and fear) are 
actually associated with lower reports of pain, or at least unassociated with higher reports of pain (Al Absi \& Rokke, 1991; Vowles et al., 2006).

\section{Perinatal Anxiety and Fear}

Negative affective states involving arousal of the autonomic nervous system, such as anxiety or fear, impact women during pregnancy, childbirth, and the postpartum period, and are associated with poor psychological health (Spice, Jones, Hadjistavropoulos, Kowalyk, \& Stewart, 2009). Perinatal anxiety is a well-established construct; however, fear is less identified with this area, except in the realm of childbirth. Approximately $23 \%$ of women experience significant anxiety during their pregnancy (Dennis, Falah-Hassani, \& Shiri, 2017). It is only natural that anxiety and fear accompany childbirth, as pregnancy involves many physiological changes, as well as discomfort and pain, possibly during pregnancy and/or labor. In industrialized cultures, most women also experience a plethora of medical procedures (Wenzel \& Stuart, 2011) during the perinatal and postpartum periods.

Some of the physiological changes that occur during pregnancy lend themselves to the development of anxiety sensitivity. In fact, fear of childbirth is partially explained by anxiety sensitivity, described as anxiety surrounding internal bodily sensations (Spice, Jones, Hadjistavropoulos, Kowalyk, \& Stewart, 2009). For example, increased progesterone can raise the possibility of hyperventilation, which is also a common symptom of panic disorder (Wenzel \& Stuart, 2011). Women who already tend to catastrophize physical symptoms may be at risk to develop panic or anxiety during pregnancy due to the occurrence of these symptoms (Wenzel \& Stuart, 2011). Additionally, elevated stress and dysregulation of the HPA-axis, which plays a pivotal role in anxiety regulation, can cause increased cortisol levels, which is the essential hormone in the body's stress response (Wenzel \& Stuart, 2011). 
Anxiety and fear during pregnancy have implications for the health of the expectant mother and her infant. Ding et al. (2014) conducted a meta-analysis evaluating studies about maternal anxiety and adverse birth outcomes. Results indicated that extant research consistently shows an association between high maternal general anxiety and pre-term birth and low birth weight (Ding et al., 2014). Pre-term birth and low birth weight can lead to health complications in infants. Perinatal anxiety is associated with other adverse outcomes including poor cognitive development in toddlers (Ibanez et al., 2015) and internalizing symptoms in children when mothers provide less physical contact (Sharp, Hill, Hellier, \& Pickles, 2015). Thus, it is crucial to understand the nature of maternal anxiety and fear, the individual characteristics that predict extreme manifestations, and how symptoms might be ameliorated. Fear of labor and childbirth, more specifically, may have additional implications for the health of the baby and the expectant mother (Stoll, Swift, Fairbrother, Nethery, \& Janssen, 2018).

\section{Fear of Pain and Fear of Labor}

The relation between fear of pain and pregnancy is not well-established, thus, for the purpose of this review, the similar and well-studied construct of fear of childbirth or labor will be discussed. Fear of the pain and medical procedures associated with labor are primary components of fear of childbirth and fear of labor in general (Klabbers, van Bakel, van den Heuvel, \& Vingerhoets, 2016). In fact, researchers suggest fear of the pain associated with childbirth may account for up to $10 \%$ of pregnancy complications, including less effective analgesia, higher use of epidural pain relief, and lower satisfaction with the childbirth process overall (Abdallah, Steyn, \& Kamel, 2019).

Fear of labor has important health implications for the women who experience it. Dencker and colleagues (2019) found that women with high fear of labor experience greater 
stress and anxiety, have greater chances of developing post-traumatic stress disorder (PTSD), and are more likely to seek psychological services after birth. Women with fear of labor also experience higher sensitivity to pain during and after their pregnancies (Saisto, Kaaja, Ylikorkala, \& Halmesmäki, 2001). Similarly, Flink, Mroczek, Sullivan, and Linton (2009) discovered that being afraid of labor and catastrophizing about potential labor pain leads women to actually experience increased pain during labor and decreased functionality during the postpartum period. Junge and colleagues (2018) also found that (before controlling for epidural administration, depression and anxiety, and menstrual pain) women with severe fear of childbirth experience increased labor pain. One study found that fear of birth during the third trimester of pregnancy is also associated with an increased risk of emergency cesarean section (Ryding, Wijma, Wijma, \& Rydhström, 1998) and an increased likliehood of choosing a cesarean section over vaginal birth (Nieminen, Stephansson, \& Ryding, 2009; Waldenström, Hildingsson, \& Ryding, 2006). It should be mentioned, however, that results about fear of childbirth and emergency cesarean section are mixed. One study found that women with high fear of childbirth were no more at risk for emergency cesarean section than women with low fear of childbirth (Jespersen, Hegaard, Schroll, Rosthøj, \& Kjærgaard, 2014). Other researchers have found that fear of labor or childbirth does not predict method of delivery at all (Heimstad, Dahloe, Laache, Skogvoll, \& Schei, 2006; Johnson \& Slade, 2002). It is possible that women with fear of labor may simply select a cesarean section over natural birth to avoid pain, or that emergency cesarean sections are predicted by an unknown third variable.

There is evidence to suggest that the human body physiologically prepares for the possible pain and negative affect associated with labor. It is well documented that the endogenous opioid peptide beta-endorphin plays a key role in regulating both pain and emotion 
(Hargreaves, Dionne, \& Mueller, 1983; Hartwig, 1991; Ribeiro, Kennedy, Smith, Stohler, \& Zubieta, 2005; Sprouse-Blum, Smith, Sugai, \& Parsa, 2010). Research shows that, during the third trimester, near the beginning of labor, beta-endorphin levels rise significantly and stay elevated after birth (Brinsmead, Smith, Singh, Lewin, \& Owens, 1985; Goebelsmann, Abboud, Hoffman, \& Hung, 1984). Beta-endorphin, combined with other hormones such as oxytocin (Brunton, 2018), may work to reduce fear of pain and pain intensity during labor or pregnancy overall. Additionally, cortisol levels steadily increase throughout pregnancy and peak during the third trimester. This increase in cortisol may provide the mother with the necessary biological resources for the metabolic needs brought about by pregnancy and labor (Jung et al., 2011). There are several variables that influence the possibility that a woman will experience fear of labor or the fear of pain associated with labor. Nulliparous women often have greater fear of labor or birth than multiparous women (Johnson \& Slade, 2002; Rouhe, Salmela-Aro, Halmesmäki, \& Saisto, 2009; Zar, Wijma, \& Wijma, 2001), which is logical given that exposure to various experiences often decreases the fear related to them (Foa \& Kozak, 1986). One case study found that exposure to movement and pain in an individual with complex regional pain syndrome significantly decreased symptoms of fear of pain and pain-related disability (de Jong et al., 2005). Another recent study found that chronic pain patients with elevated fear of pain had reduced levels of cortisol after engaging in exposure treatment for pain (Schemer et. al, 2018). These findings demonstrate that it is possible for fear of pain to be reduced through experiences with pain. Thus, women with prior birth experience may experience lower fear of pain or labor. Additionally, nulliparous women who have high fear of childbirth have also been shown to have low birth self-efficacy (Salomonsson, Gullberg, Alehagen, \& Wijma, 2013), which may not be as relevant to parous women as they have already successfully completed a birth. 
As was previously mentioned, culture may also impact the way that women view labor pain after the birth of a child. In fact, one study found that relative to other European countries, women in Turkey experience severe fear of childbirth due to cultural expectations surrounding birth (Deliktas \& Kukulu, 2019). Other studies have implicated important factors that differ among cultures, such as education and employment rates, as predictive of fear of childbirth during pregnancy. In women living in Malawi, researchers found that illiteracy and unemployment emerged as factors that made women more likely to experience moderate to high levels of fear of childbirth (Khwepeya, Lee, Chen, \& Kuo, 2018). While this finding is unique to women living in Malawi, unemployment, poverty, and low quality of education are factors that impact some parts of Appalachia and rural areas generally (Lobao, Zhou, Partridge, \& Betz, 2016; Singh, Kogan, \& Slifkin, 2017).

\section{Appalachian Culture and Pain}

While research has been conducted on a variety of racial/ethnic groups and their expression of pain and treatment disparities (Hadjistavropoulos \& Craig, 2004), little research on fearfulness about pain has been conducted in Appalachia. Appalachia is both a place, and a way of being. The Appalachian region spans 13 states in the eastern USA and includes rural and industrial areas (Appalachian Regional Commission, 2019).

People living in Appalachia face several environmental threats to their health, associated with occupations involving coal, natural gas, and timber (Ludke \& Obermiller, 2012; Zullig \& Hendryx, 2010) and experience disparities in oral and overall health (Lane et al., 2012; Ludke \& Obermiller, 2012; Martin et al., 2008; McNeil, Crout, \& Marazita, 2012). Some of those who reside in Appalachia, particularly in rural areas, face a lack of available health services, low utilization of health services, limited health literacy, and lack of managed care (Ludke \& 
Obermiller, 2012, pp. 90-94). Given these conditions, it is paramount that additional research be conducted to inform and improve the healthcare of the people of the Appalachian region.

Some individuals living in Appalachia lead a life that is very rural. This lifestyle has influenced the way that individuals in Appalachia have experienced and coped with pain and related emotional states. Several occupations in Appalachia involve manual labor, which can lead to disability. Partially due to the rate of disability, Appalachia has been disproportionately affected by the American opioid crisis which has plagued the USA as a whole (Chubinski, Walsh, Sallee, \& Rademacher, 2014; Miller, 2004). There were over 42,000 opioid deaths in the USA in 2016 alone, and approximately 7,000 of these deaths occurred in Appalachia (Opioid Use in Medicare Part D in States in the Appalachian Region, 2018). The opioid epidemic does not just affect the individuals suffering from addiction, but also their families. One study found that babies born in rural Appalachian regions are 2-2.25 times more likely to be born with Neonatal Abstinence Syndrome as a result of opioid use during pregnancy; further, the mothers did not have adequate access to an addiction treatment program (Brown, Goodin, \& Talbert, 2018). Thus, the management of pain and its co-morbid concerns are significant problems facing Appalachia.

It is also possible, however, given the nature of the rural, family-oriented, and independent lifestyle of some Appalachian people (Jones, 1994), they have protective factors for dealing with pain. Indeed, some research has indicated that the prominent religiosity of individuals living in Appalachia may play a protective role for anxiety, or in fostering resilience generally (Photiadis \& Schnabel, 1977). Recent research supports the notion that this effect may be occurring in medical settings as well, as one sample of individuals who reported being highly spiritual were shown to have better psychological functioning and pain-related resilience (e.g., 
ignoring pain sensations, coping self-statements; Ferreira-Valente, Damião, Pais-Ribeiro, \& Jensen, 2019). Appalachians also display a strong sense of self-efficacy and a do-it-yourself mentality (Jones, 1994). Previous research indicates that greater self-efficacy is related to fewer pain behaviors (Buescher, 1991) and psychological resilience to pain (Leung \& Cheng, 2018). Thus, research is needed to determine possible differences in fear of pain between individuals living inside and outside of the Appalachian region.

\section{Statement of the Problem}

The aim of the current study was to understand how pregnancy and Appalachian culture affect fear of pain. Such research could inform women's health and treatment, as well as improve pain treatment in Appalachia and beyond.

\section{Hypotheses}

Given the findings of previous research, the hypotheses were:

H1: Fear of pain will be lower in pregnant women than non-pregnant women.

H2: Fear of pain will be lower in Appalachian women than those of a comparison sample from the USA outside of Appalachia (While the opposite hypothesis could be predicted, given the nature of the opioid epidemic in Appalachia and elsewhere, other research suggests that Appalachian culture may promote an attenuation of anxiety and fear (McNeil et al., 2019).

H3: There will be an interaction between pregnancy and Appalachian culture such that the lowest level of pain-related fear will be reported by women who are pregnant and living in Appalachia, while the highest level of pain-related fear will be reported by women who are not pregnant and are living in the USA outside of Appalachia (This interaction was predicated on the possibility that a combination of being pregnant and living in Appalachia may bestow additive or synergistic protective effects on pain-related fear). 
H4: Women who have given birth one or more times will have lower fear of pain than those who are nulliparous.

\section{Method}

\section{Design}

The study involved a 2 (pregnant vs. non-pregnant) x 2 (Appalachian vs. nonAppalachian) between-subjects design. This study also involved examining mean differences between nulliparous women (never given birth) and parous/multiparous women (one or more births). Institutional Review Board (IRB) approval was obtained at West Virginia University (Protocol number: 1905587570).

\section{Sample Size Determination}

The study had two factors (i.e., culture and pregnancy status), and utilized archival data as well as new data collection. Alpha was set at 0.05 , therefore, power will be 0.95 . Through the use of the power analysis program $G *$ Power 3 (Faul, Erdfelder, Lang, \& Buchner, 2007), results indicated that in order to achieve a small effect size with the proposed statistical analysis, targeted at $\eta_{\mathrm{p}}{ }^{2}=0.15$, the total sample size needed to consist of at least 148 participants.

\section{Data Sources}

Data from pregnant and non-pregnant Appalachian women of child-bearing age (18-45 years) were acquired through two cohorts from the Center for Oral Health Research in Appalachia (COHRA) projects. COHRA1 is a family-based study that focused on identifying the factors that affect oral health in Appalachia's children (Polk et. al, 2008). COHRA2 is a study focused on mother-child dyads and the relation between risk factors and the development of dental caries and oral diseases from pregnancy through early childhood (Neiswanger et. al, 2015). Comparison data from pregnant and non-pregnant women in the USA were obtained from 
Amazon's Mechanical Turk (MTurk). MTurk is an online mechanism that allows for fast, inexpensive, and representative data collection. Typical MTurk samples are more racially and ethnically diverse than standard internet samples (36\% non-white vs. $23 \%$ non-white) and have a greater mean age than typical internet samples or undergraduate samples $(M=32.8, S D=11.5$ vs. $M=24.3, S D=10.0$; Buhrmester, Kwang, \& Gosling, 2011). While data collection on MTurk does have limitations (i.e., population is often more liberal, issue of self-selection), some of these issues can be addressed by restricting collection (e.g., individuals from USA only, or certain parts of it, only women, certain age groups; Berinsky, Huber, \& Lenz, 2012).

\section{Participants}

New data were collected from a sample of 46 non-pregnant women and 46 pregnant women at least 18 and under the age of 45 from the USA outside of Appalachia. Participants were be limited by age to reflect child-bearing years. They were excluded if they reported that they live a county that is included in the Appalachian region. Women were recruited through Amazon's Mechanical Turk (MTurk).

Data from 46 women in the COHRA1 dataset, 46 women in the COHRA2 dataset, and 46 non-pregnant women from the MTurk sample were age-matched using a random number table to the 46 pregnant non-Appalachian women from the MTurk sample.

A total of 13 of the participants collected via MTurk were excluded (9 for being from an Appalachian county, 2 for incomplete/missing data, 2 for using the same IP address with different responses).

\section{Measures}

Fear of Pain. In order to assess fear of pain, the Fear of Pain Questionnaire-9 (FPQ-9; McNeil et. al, 2018) were administered. The FPQ-9 evaluates fear of pain generally and is 
comprised of 3 different subscales with 3 items each: fear of severe pain, fear of minor pain, and fear of medical/dental pain. The measure yields a reliable total score and three subscale scores. The FPQ-9 has total coefficient alpha values ranging from 0.72 to 0.84 . Concurrent validity was demonstrated through significant correlations between the subscales and total score of the Fear of Pain Questionnaire-III (McNeil \& Rainwater, 1998; $p<.01$ ). The subscale and total scores of the FPQ-9 also have been found to generally correspond to the subscales and the total score of the Pain Anxiety Symptoms Scale (PASS; McCracken, Zayfert, \& Gross, 1992; $p<.01$ ). The FPQ-9 questionnaire can be found in Appendix A.

Demographics. Participants reported on age, race/ethnicity, county of residence, and state of residence. They then reported on their history of childbirth: number of pregnancies, number of births, type of births (e.g., Cesarean section, epidural medicated birth, other medicated birth, unmedicated birth), and number of biological children. The demographic form is located in Appendix B and contains questions that are part of a larger study.

\section{Procedure}

Participants were recruited through MTurk, as previously mentioned, and were compensated monetarily for their participation, one dollar for approximately 20 minutes of participation. Participants completed demographic measures, along with measures from an unrelated study, and the FPQ-9. There were four validity items included throughout the survey in

order to ensure that participants answered in a logical fashion and attended to the survey (Wright, 2018). These items are in Appendix C.

\section{Analytic Strategy}

In order to test hypotheses 1, 2, and 3, a 2 (pregnancy status) x 2 (Appalachian culture vs. non-Appalachian) univariate analysis of variance was conducted with total fear of pain as the 
dependent variable. Main effects were determined for pregnancy status and Appalachian cultural membership. An interaction effect was obtained as well. To investigate hypothesis 4, a Student's $t$-test was conducted to compare nulliparous women's level of pain-related fear to that of women who have had one or more prior births.

\section{Results}

The final sample for the study consisted of 184 women $(M$ age $=30.6$ years, $S D=5.4)$ : 46 pregnant non-Appalachian women, 46 non-pregnant non-Appalachian women, 46 pregnant Appalachian women, and 46 non-pregnant Appalachian women. Ethnic/racial distribution was white/Caucasian (88\%, $n=162)$, African American $(6 \%, n=11)$, Asian $(3.3 \%, n=6)$, Hispanic or Latino $(2.2 \%, \mathrm{n}=4)$, Native Hawaiian or Pacific Islander $(0.5 \%, \mathrm{n}=1)$, and Native American $(0 \%, \mathrm{n}=0)$.

\section{Hypotheses 1-3}

The first hypothesis was that pregnant women would report lower levels of pain-related fear when compared to non-pregnant women. Based on the ANOVA, the main effect of pregnancy was significant $\left(F=11.22, p<.01, \eta_{\mathrm{p}}{ }^{2}=.06\right)$, such that pregnant women reported lower levels of pain-related fear $(M=22.7, S D=6.4)$ than non-pregnant women $(M=25.90, S D$ $=7.0)$.

The second hypothesis stated that women living in Appalachia would report lower levels of pain-related fear when compared to women who do not live in Appalachia. Based on the ANOVA, the main effect of region was significant $\left(F=8.03, p<.01, \eta_{\mathrm{p}}^{2}=.04\right)$, such that women living in Appalachia reported lower levels of pain-related fear $(M=22.9, S D=7.6)$ than women living outside of Appalachia $(M=25.7, S D=5.8)$. 
The third hypothesis stated that there would be an interaction between pregnancy status and region, such that pregnant Appalachian women would have the lowest levels of fear of pain. Contrary to the hypothesis, the interaction between region and pregnancy status was not significant $\left(F=.564, p=.454, \eta_{\mathrm{p}}^{2}=.003 ;\right.$ See Figure 1$)$.

\section{Hypothesis IV}

The fourth hypothesis posited that women with one or more prior births would experience lower levels of fear of pain than women with no prior births. In contrast to the hypothesis, as determined by a $t$-test, differences in fear of pain between women with one or more prior births $(M=23.9, S D=7.3)$ and women with no prior births $(M=25.0, S D=6.0)$ were not significant $(t(176)=.97, p=.33)$. When the subscales of the FPQ-9 were examined, however, fear of severe pain did emerge as significantly different $(t(176)=1.95, p=.05)$ such that women with one or more prior births were less fearful $(M=10.4, S D=3.2)$ than women with no prior births $(M=11.3, S D=2.7)$. There were no significant differences between women with one or more prior births $(M=7.6, S D=2.8)$ and women with no prior births $(M=7.8, S D=$ 2.7) in fear of medical or dental pain $(t(176)=0.51, p=.61)$. Additionally, there were no significant differences between women with one or more prior births $(M=6.0, S D=2.5)$ and women with no prior births $(M=5.9, S D=2.1)$ in fear of minor pain $(t(176)=-0.26, p=.80)$.

\section{Discussion}

Pregnancy and living in Appalachia each may involve unique protective factors that diminish fear of pain. Results indicated that there was both a main effect of pregnancy status and a main effect of living in the Appalachian region on fear of pain. Pregnant women reported significantly lower pain-related fear than non-pregnant women, and Appalachian women reported significantly lower pain-related fear than women living outside of Appalachia. There 
was, however, no significant interaction between these living in Appalachia and pregnancy status, which suggests that these two factors have independent and possibly unrelated effects on fear of pain.

Research in Appalachia is typically focused on the risk factors associated with living in the region such as increased prevalence of chronic health conditions. In this study, living in Appalachia was hypothesized to be a protective factor. Future research is needed to determine the mechanism that explains the association between living in Appalachia and lower fear of pain. Prior research has identified high self-efficacy as a protective factor for pain. Those living in Appalachia report higher rates of self-efficacy relative to the rest of the USA (Jones, 1994) therefore, self-efficacy should be investigated as a potential mechanism in this relation.

It is possible that biological mechanisms are in place during pregnancy to protect women from pain and related fear and anxiety. Previous research indicates that estrogen is related to pain modulation, such that increased levels of estrogen are associated with lower pain sensitivity, and biologically, increased endogenous opioid levels (Straneva, Maixner, Light, Pedersen, Costello, $\&$ Girdler, 2002). Experiencing reduced pain sensitivity may be associated with experiencing lower fear of pain.

Additionally, there was no effect of parity on fear of pain broadly, however, there was a parity effect in the FPQ-9 subscale of fear of severe pain. These results, when examined holistically, complement studies that have found an effect of parity on fear of labor in women in the past. Perhaps women who already have experienced childbirth learn to cope with pain, such that fear about labor, and about severe pain in general, are reduced. While birth experiences may serve an exposure-like effect on fear of severe pain and fear of labor more generally, they did not seem to impact the other areas measured by the FPQ-9 (e.g., fear of minor pain, fear of medical 
or dental pain). Pain-related fear and fear of labor are distinct constructs, so this may partially explain the contradictory findings. Additional research is needed to understand the potential exposure effects of labor, and if pain truly is a key component of fear of labor. Given the findings described previously, it is also possible that these results would be different if the analyses were conducted by group (i.e., comparing those living inside or outside of Appalachia, or those pregnant or non-pregnant). Future research may evaluate the exposure effect of parity and how it may differ depending on the culture of the sample.

While this study was limited by its racially and ethnically homogenous sample, this may also be a strength because the focus of the study was on an underrepresented and understudied group, women in Appalachia. The study was also limited in its categorization of individuals living in Appalachia or the only criterion was residency at the time of the study. Birthplace, length of time in Appalachia, and Appalachian identity were not considered, nor was the urban or rural nature of the residency. Women recruited from mTurk completed the study through a series of online self-report questionnaires, while women from the COHRA1 and COHRA2 cohorts completed the study measures in person with a research assistant. This difference in procedure cannot be ruled out as a potential confounding variable. Additionally, the study was limited by its use of only self-report measures, which may be biased by social desirability. It is possible that the sample of Appalachian women that completed the study self-selected to participate from more urban or more rural regions of Appalachia. Future research may address potential differences in fear of pain among urban and rural Appalachians, to ascertain if there are indeed differences between these communities. Additionally, in this research, there was no measure of Appalachian identity, and women were included in the sample regardless of how long they lived in Appalachia. That being said, not all women living in Appalachia may identify 
as Appalachian or feel that their cultural identity is important to them. These women may have moved to Appalachia from another area of the USA and may even identify more with their prior place of residence. Thus, additional research in this area should focus on how Appalachian identity or length of time living in the Appalachian region play a role in the protective factors identified in this study.

The mean differences in FPQ-9 scores observed here involve only 1-3 points on scales that span 12-36 points. While the differences identified in this study may not be substantive, in a non-clinical population, they may be well be meaningful. Future research might utilize behavioral or physiological measures of fear. Given that self-report measures were used, it is possible that individuals were underreporting or overreporting fear of pain levels. Likewise, imminence of pain experience could have affected pain reporting. For example, had the experience of undergoing labor or birth been temporally closer (e.g., third trimester versus first or second trimester), pregnant women may have been more likely to report higher levels of painrelated fear.

Nevertheless, these findings reveal important cultural and life course factors that contribute to the broader literature on multiculturalism and women's health. Pregnancy is a unique and complex state associated with many biological and psychological changes. Given the negative consequences associated with fear during pregnancy, it is quite possible that there are biologically protective processes to prevent fear of pain. The findings of this study provide and exciting direction for future research into the biological mechanisms that prevent or mediate fear of pain during pregnancy. Additionally, women living in Appalachia have lower levels of fear of pain, suggesting that there is a unique aspect of Appalachian life that is protective against fear of 
pain broadly, or at the least, impact verbal reporting of fear of pain. Future research is needed to discover the exact nature of this protective mechanism.

There are many independent benefits to being pregnant, and also to living in Appalachia. There also are, however, health concerns related to pregnancy and to living in this region. These findings shed some light on an important but underrepresented group, pregnant women living in Appalachia, demonstrating positive influences and possibly protective factors related to fear and anxiety associated with pain. 


\section{References}

Abdallah, R., Steyn, P. P., \& Kamel, I. (2019). Factors influencing the perception of pain in pregnancy. In: Abd-Elsayed, A. (Eds.) Pain (pp. 989-992). Springer, Cham.

Appalachian Regional Commission (n.d.). About ARC. Retrieved April 17, 2019, from https://www.arc.gov/about/index.asp.

Asmundson, G. J., \& Taylor, S. (1996). Role of anxiety sensitivity in pain-related fear and avoidance. Journal of Behavioral Medicine, 19(6), 577-586.

Al Absi, M., \& Rokke, P. D. (1991). Can anxiety help us tolerate pain?. Pain, 46(1), 43-51.

Berinsky, A. J., Huber, G. A., \& Lenz, G. S. (2012). Evaluating online labor markets for experimental research: Amazon.com's mechanical turk. Political Analysis, 20(3), 351368.

Brinsmead, M., Smith, R., Singh, B., Lewin, T., \& Owens, P. (1985). Peripartum concentrations of beta endorphin and cortisol and maternal mood states. Australian and New Zealand Journal of Obstetrics and Gynaecology, 25(3), 194-197.

Brunton, P. J. (2018). Endogenous opioid signaling in the brain during pregnancy and lactation. Cell and Tissue Research, 375(1), 69-83.

Buescher, K. L., Johnston, J. A., Parker, J. C., Smarr, K. L., Buckelew, S. P., Anderson, S. K., \& Walker, S. E. (1991). Relationship of self-efficacy to pain behavior. Journal of Rheumatology, 18(7), 968-972.

Buhrmester, M., Kwang, T., \& Gosling, S. D. (2011). Amazon's Mechanical Turk: A new source of inexpensive, yet high-quality, data? Perspectives on Psychological Science, 6(1), 3-5. 
Brown, J. D., Goodin, A. J., \& Talbert, J. C. (2018). Rural and Appalachian disparities in neonatal abstinence syndrome incidence and access to opioid abuse treatment. Journal of Rural Health, 34(1), 6-13.

Chubinski, J., Walsh, S., Sallee, T., \& Rademacher, E. (2014). Painkiller misuse among Appalachians and in Appalachian counties in Kentucky. Journal of Appalachian Studies, 20(2), 154-169.

Curzik, D., \& Jokic-Begic, N. (2011). Anxiety sensitivity and anxiety as correlates of expected, experienced and recalled labor pain. Journal of Psychosomatic Obstetrics \& Gynecology, 32(4), 198-203.

Dalton, E., \& Miller, L. (2016). Peers, stereotypes and health communication through the cultural lens of adolescent Appalachian mothers. Culture, Health \& Sexuality, 18(2), 115 128.

de Jong, J. R., Vlaeyen, J. W., Onghena, P., Cuypers, C., den Hollander, M., \& Ruijgrok, J. (2005). Reduction of pain-related fear in complex regional pain syndrome type I: the application of graded exposure in vivo. Pain, 116(3), 264-275.

Deliktas, A., \& Kukulu, K. (2019). Pregnant women in Turkey experience severe fear of childbirth: A systematic review and meta-analysis. Journal of Transcultural Nursing, $30(5), 501-511$

Demmelmaier, I., Björk, A., Dufour, A. B., Nordgren, B., \& Opava, C. H. (2018). Trajectories of fear-avoidance beliefs on physical activity over two years in people with rheumatoid arthritis. Arthritis Care \& Research, 70(5), 695-702. 
Dencker, A., Nilsson, C., Begley, C., Jangsten, E., Mollberg, M., Patel, H., ... \& Sparud-Lundin, C. (2019). Causes and outcomes in studies of fear of childbirth: A systematic review. Women and Birth, 32(2), 99-111.

Dennis, C. L., Falah-Hassani, K., \& Shiri, R. (2017) Prevalence of antenatal and postnatal anxiety: Systematic review and meta-analysis. British Journal of Psychiatry, 210(05), $315-323$.

Ding, X. X., Wu, Y. L., Xu, S. J., Zhu, R. P., Jia, X. M., Zhang, S. F., .. \& Tao, F. B. (2014). Maternal anxiety during pregnancy and adverse birth outcomes: A systematic review and meta-analysis of prospective cohort studies. Journal of Affective Disorders, 159, 103-110.

Faul, F., Erdfelder, E., Lang, A. G., \& Buchner, A. (2007). G* Power 3: A flexible statistical power analysis program for the social, behavioral, and biomedical sciences. Behavior Research Methods, 39(2), 175-191.

Ferreira-Valente, A., Damião, C., Pais-Ribeiro, J., \& Jensen, M. P. (2019). The role of spirituality in pain, function, and coping in individuals with chronic pain. Pain Medicine, pnz092, https://doi.org/10.1093/pm/pnz092.

Foa, E. B., \& Kozak, M. J. (1986). Emotional processing of fear: Exposure to corrective information. Psychological Bulletin, 99(1), 20-35.

Flink, I. K., Mroczek, M. Z., Sullivan, M. J., \& Linton, S. J. (2009). Pain in childbirth and postpartum recovery-The role of catastrophizing. European Journal of Pain, 13(3), 312316.

Fritz, J. M., George, S. Z., \& Delitto, A. (2001). The role of fear-avoidance beliefs in acute low back pain: Relationships with current and future disability and work status. Pain, 94(1), $7-15$. 
Gerrits, M. M., van Marwijk, H. W., van Oppen, P., van der Horst, H., \& Penninx, B. W. (2015). Longitudinal association between pain, and depression and anxiety over four years. Journal of Psychosomatic Research, 78(1), 64-70.

Goebelsmann, U., Abboud, T. K., Hoffman, D. I., \& Hung, T. T. (1984). Beta-endorphin in pregnancy. European Journal of Obstetrics \& Gynecology and Reproductive Biology, 17, $77-89$.

Green, C. R., Baker, T. A., \& Ndao-Brumblay, S. K. (2004). Patient attitudes regarding healthcare utilization and referral: a descriptive comparison in African-and Caucasian Americans with chronic pain. Journal of the National Medical Association, 96(1), 31.

Gross, R. T., and Collins, F. L., Jr. (1981). On the relationship between anxiety and pain: A methodological confounding. Clinical Psychology Review, 1(3), 375-386.

Hadjistavropoulos, T., \& Craig, K. D. (2004). Pain: Psychological perspectives. Psychology Press.

Hargreaves, K. M., Dionne, R. A., \& Mueller, G. P. (1983). Plasma beta-endorphin-like immunoreactivity, pain and anxiety following administration of placebo in oral surgery patients. Journal of Dental Research, 62(11), 1170-1173.

Hartwig, A. C. (1991). Peripheral beta-endorphin and pain modulation. Anesthesia Progress, 38(3), 75-78.

Heimstad, R., Dahloe, R., Laache, I., Skogvoll, E., \& Schei, B. (2006). Fear of childbirth and history of abuse: implications for pregnancy and delivery. Acta Obstetricia et Gynecologica Scandinavica, 85(4), 435-440.

Hoehn-Saric, R. \& McLeod, D. R. (1988). The peripheral sympathetic nervous system: Its role in normal and pathologic anxiety. Psychiatric Clinics, 11(2), 375-386. 
Ibanez, G., Bernard, J. Y., Rondet, C., Peyre, H., Forhan, A., Kaminski, M., ... \& EDEN MotherChild Cohort Study Group. (2015). Effects of antenatal maternal depression and anxiety on children's early cognitive development: A prospective cohort study. PloS One, 10(8), e0135849.

Jespersen, C., Hegaard, H. K., Schroll, A. M., Rosthøj, S., \& Kjærgaard, H. (2014). Fear of childbirth and emergency caesarean section in low-risk nulliparous women: a prospective cohort study. Journal of Psychosomatic Obstetrics \& Gynecology, 35(4), 109-115.

Johnson, R., \& Slade, P. (2002) Does fear of childbirth predict emergency caesarean section? BJOG: An International Journal of Obstetrics and Gynaecology, 109, 1213-1221.

Jones, L. (1994). Appalachian values. Ashland, KY: Jesse Stuart Foundation.

Jung, C., Ho, J. T., Torpy, D. J., Rogers, A., Doogue, M., Lewis, J. G., ... \& Inder, W. J. (2011). A longitudinal study of plasma and urinary cortisol in pregnancy and postpartum. Journal of Clinical Endocrinology \& Metabolism, 96(5), 1533-1540.

Junge, C., von Soest, T., Weidner, K., Seidler, A., Eberhard-Gran, M., \& Garthus-Niegel, S. (2018). Labor pain in women with and without severe fear of childbirth: A populationbased, longitudinal study. Birth. 45(4), 469-477.

Keller, P. S., Bi, S., \& Schoenberg, N. (2019). Children being reared by their grandparents in rural Appalachia: A pilot study of relations between psychosocial stress and changes in salivary markers of inflammation over time. Journal of Child \& Adolescent Trauma, $12(2), 269-277$.

Khwepeya, M., Lee, G. T., Chen, S. R., \& Kuo, S. Y. (2018). Childbirth fear and related factors among pregnant and postpartum women in Malawi. BMC pregnancy and childbirth, 18(1), 391. 
Klabbers, G. A., van Bakel, H. J., van den Heuvel, M., \& Vingerhoets, A. J. (2016). Severe fear of childbirth: Its features, assessment, prevalence, determinants, consequences and possible treatments. Psychological Topics, 25(1), 107-127.

Klages, U., Ulusoy, Ö., Kianifard, S., \& Wehrbein, H. (2004). Dental trait anxiety and pain sensitivity as predictors of expected and experienced pain in stressful dental procedures. European Journal of Oral Sciences, 112(6), 477-483.

Lane, N. M., Lutz, A. Y., Baker, K., Konrad, T. R., Ricketts, T. C., Randolph, R., ... \& Beadles, C. A. (2012). Health care costs and access disparities in Appalachia. PDA, Incorporated.

Leeuw, M., Goossens, M. E., Linton, S. J., Crombez, G., Boersma, K., \& Vlaeyen, J. W. (2007). The fear-avoidance model of musculoskeletal pain: Current state of scientific evidence. Journal of Behavioral Medicine, 30(1), 77-94.

Leung, M., \& Cheng, S. (2018). A moderated mediation model of self-efficacy, catastrophizing and depressive symptoms in chronic pain patients. Innovation in Aging, 2(Suppl 1), 667.

Linton, S. J., \& Shaw, W. S. (2011). Impact of psychological factors in the experience of pain. Physical Therapy, 91(5), 700-711.

Lobao, L., Zhou, M., Partridge, M., \& Betz, M. (2016). Poverty, place, and coal employment across Appalachia and the United States in a new economic era. Rural Sociology, 81(3), 343-386.

Ludke, R. L., \& Obermiller, P. J. (2012). Appalachian health and well-being. Lexington, KY. University Press of Kentucky.

Martin, C. A., McNeil, D. W., Crout, R. J., Ngan, P. W., Weyant, R. J., Heady, H. R., \& Marazita, M. L. (2008). Oral health disparities in Appalachia: Orthodontic treatment need and demand. Journal of the American Dental Association, 139(5), 598-604. 
McCracken, L. M., Zayfert, C., \& Gross, R. T. (1992). The Pain Anxiety Symptoms Scale: Development and validation of a scale to measure fear of pain. Pain, 50(1), 67-73.

McNeil, D., Arias, M. \& Randall, C. (2017). Anxiety versus fear. In A. Wenzel (Ed.), The sage encyclopedia of abnormal and clinical psychology (Vol. 1, pp. 279-280). Thousand Oaks, CA: Sage.

McNeil, D. W., Crout, R. J., \& Marazita, M. L. (2012). Oral health in Appalachia. In R. L. Ludke \& P. J. Obermiller, P. J. (Eds.), Appalachian health and well-being (pp. 275294). Lexington, KY: University Press of Kentucky.

McNeil, D. W., Kennedy, S. G., Randall, C. L., Addicks, S. H., Wright, C. D., Hursey, K. G., \& Vaglienti, R. (2018). Fear of Pain Questionnaire-9: Brief assessment of pain-related fear and anxiety. European Journal of Pain, 22, 39-48.

McNeil, D.W. \& Rainwater, A. J. III. (1998). Development of the Fear of Pain Questionnaire-III. Journal of Behavioral Medicine, 21(4), 389-410.

McNeil, D., Randall, C., Cohen, L., Crout, R., Weyant, R., Neiswanger, K., \& Marazita, M. (2019). Transmission of dental fear from parent to adolescent in an Appalachian sample in the USA. International Journal of Paediatric Dentistry, 29(6), 720-727. doi:10.1111/ipd.12564

Miller, S. E. (2004). A climate ripe for abuse: The role of Kentucky's workers' compensation law in perpetuating drug abuse in the Appalachian region. Kentucky Law Journal, 93, 243.

Neiswanger, K., McNeil, D. W., Foxman, B., Govil, M., Cooper, M. E., Weyant, R. J., ... \& Chapman, S. (2015). Oral health in a sample of pregnant women from Northern Appalachia (2011-2015). International Journal of Dentistry, 2015. 
Nieminen, K., Stephansson, O., \& Ryding, E. L. (2009). Women's fear of childbirth and preference for cesarean section-a cross-sectional study at various stages of pregnancy in Sweden. Acta Obstetricia et Gynecologica Scandinavica, 88(7), 807-813.

Opioid Use in Medicare Part D in States in the Appalachian Region. (2018, December 17). Retrieved November 13, 2019, from https://oig.hhs.gov/reports-andpublications/workplan/summary/wp-summary-0000354.asp.

Pfingsten, M., Leibing, E., Harter, W., Kröner-Herwig, B., Hempel, D., Kronshage, U., \& Hildebrandt, J. (2001). Fear-avoidance behavior and anticipation of pain in patients with chronic low back pain: a randomized controlled study. Pain Medicine, 2(4), 259-266.

Ploghaus, A., Narain, C., Beckmann, C. F., Clare, S., Bantick, S., Wise, R., ... \& Tracey, I. (2001). Exacerbation of pain by anxiety is associated with activity in a hippocampal network. Journal of Neuroscience, 21(24), 9896-9903.

Polk, D. E., Weyant, R. J., Crout, R. J., McNeil, D. W., Tarter, R. E., Thomas, J. G., \& Marazita, M. L. (2008). Study protocol of the Center for Oral Health Research in Appalachia (COHRA) etiology study. BMC Oral Health, 8(1), 18.

Rhudy, J. L., \& Meagher, M. W. (2000). Fear and anxiety: Divergent effects on human pain thresholds. Pain, 84(1), 65-75.

Ribeiro, S. C., Kennedy, S. E., Smith, Y. R., Stohler, C. S., Zubieta, J. K. (2005). Interface of physical and emotional stress regulation through the endogenous opioid system and $\mu$ opioid receptors. Progress in Neuro-Psychopharmacology \& Biological Psychiatry, 29, 1264-1280. 
Rouhe, H., Salmela-Aro, K., Halmesmäki, E., \& Saisto, T. (2009). Fear of childbirth according to parity, gestational age, and obstetric history. BJOG: An International Journal of Obstetrics \& Gynaecology, 116(1), 67-73.

Ryding, E., Wijma, B., Wijma, K., \& Rydhström, H. (1998). Fear of childbirth during pregnancy may increase the risk of emergency cesarean section. Acta Obstetricia et Gynecologica Scandinavica, 77(5), 542-547.

Saisto, T., Kaaja, R., Ylikorkala, O., \& Halmesmäki, E. (2001). Reduced pain tolerance during and after pregnancy in women suffering from fear of labor. Pain, 93(2), 123-127.

Salomonsson, B., Gullberg, M. T., Alehagen, S., \& Wijma, K. (2013). Self-efficacy beliefs and fear of childbirth in nulliparous women. Journal of Psychosomatic Obstetrics \& Gynecology, 34(3), 116-121.

Schemer, L., Vlaeyen, J. W., Doerr, J. M., Skoluda, N., Nater, U. M., Rief, W., \& Glombiewski, J. A. (2018). Treatment processes during exposure and cognitive-behavioral therapy for chronic back pain: A single-case experimental design with multiple baselines. Behaviour Research and Therapy, 108, 58-67.

Sharp, H., Hill, J., Hellier, J., \& Pickles, A. (2015). Maternal antenatal anxiety, postnatal stroking and emotional problems in children: Outcomes predicted from pre-and postnatal programming hypotheses. Psychological Medicine, 45(2), 269-283.

Singh, G. K., Kogan, M. D., \& Slifkin, R. T. (2017). Widening disparities in infant mortality and life expectancy between Appalachia and the rest of the United States, 1990-2013. Health Affairs, 36(8), 1423-1432. 
Spice, K., Jones, S. L., Hadjistavropoulos, H. D., Kowalyk, K., \& Stewart, S. H. (2009). Prenatal fear of childbirth and anxiety sensitivity. Journal of Psychosomatic Obstetrics \& Gynecology, 30(3), 168-174.

Sprouse-Blum, A. S., Smith, G., Sugai, D., \& Parsa, F. D. (2010). Understanding endorphins and their importance in pain management. Hawaii Medical Journal, 69(3), 70.

Stoll, K., Swift, E. M., Fairbrother, N., Nethery, E., \& Janssen, P. (2018). A systematic review of nonpharmacological prenatal interventions for pregnancy-specific anxiety and fear of childbirth. Birth, 45(1), 7-18.

Straneva, P. A., Maixner, W., Light, K. C., Pedersen, C. A., Costello, N. L., \& Girdler, S. S. (2002). Menstrual cycle, beta-endorphins, and pain sensitivity in premenstrual dysphoric disorder. Health Psychology, 21(4), 358.

Swinkels-Meewisse, I. E., Roelofs, J., Oostendorp, R. A., Verbeek, A. L., \& Vlaeyen, J. W. (2006). Acute low back pain: pain-related fear and pain catastrophizing influence physical performance and perceived disability. Pain, 120(1-2), 36-43.

Vlaeyen, J. W., Crombez, G., \& Linton, S. J. (2016). The fear-avoidance model of pain. Pain, 157(8), 1588-1589.

Vlaeyen, J. W., Kole-Snijders, A. M., Rotteveel, A. M., Ruesink, R., \& Heuts, P. H. (1995). The role of fear of movement/(re) injury in pain disability. Journal of Occupational Rehabilitation, 5(4), 235-252.

Vlaeyen, J. W., \& Linton, S. J. (2012). Fear-avoidance model of chronic musculoskeletal pain: 12 years on. Pain, 153(6), 1144-1147. 
Vowles, K. E., McNeil, D. W., Sorrell, J. T., \& Lawrence, S. M. (2006). Fear and pain:

Investigating the interaction between aversive states. Journal of Abnormal Psychology, 115(4), 821-833.

Waldenström, U., Hildingsson, I., \& Ryding, E. L. (2006). Antenatal fear of childbirth and its association with subsequent caesarean section and experience of childbirth. BJOG: An International Journal of Obstetrics \& Gynaecology, 113(6), 638-646.

Wenzel, A., \& Stuart, S. C. (2011). Anxiety in childbearing women: Diagnosis and treatment. Washington, DC: American Psychological Association.

Wijma, K., Wijma, B., \& Zar, M. (1998). Psychometric aspects of the W-DEQ; a new questionnaire for the measurement of fear of childbirth. Journal of Psychosomatic Obstetrics \& Gynecology, 19(2), 84-97.

Wilson, S. L., Kratzke, C., \& Hoxmeier, J. (2012). Predictors of access to healthcare: What matters to rural Appalachians?. Global Journal of Health Science, 4(6), 23.

Withers, M., Kharazmi, N., \& Lim, E. (2018). Traditional beliefs and practices in pregnancy, childbirth and postpartum: a review of the evidence from Asian countries. Midwifery, 56, $158-170$.

Wright, C. D. (2018). Fear of pain across the adult lifespan. Master's Thesis, West Virginia University, Morgantown, West Virginia.

Zar, M., Wijma, K., \& Wijma, B. (2001). Pre-and postpartum fear of childbirth in nulliparous and parous women. Scandinavian Journal of Behaviour Therapy, 30(2), 75-84.

Zullig, K. J., \& Hendryx, M. (2010). A comparative analysis of health-related quality of life for residents of US counties with and without coal mining. Public Health Reports, 125(4), 548-555. 
Figure 1

Differences in Fear of Pain: Pregnancy Status X Region

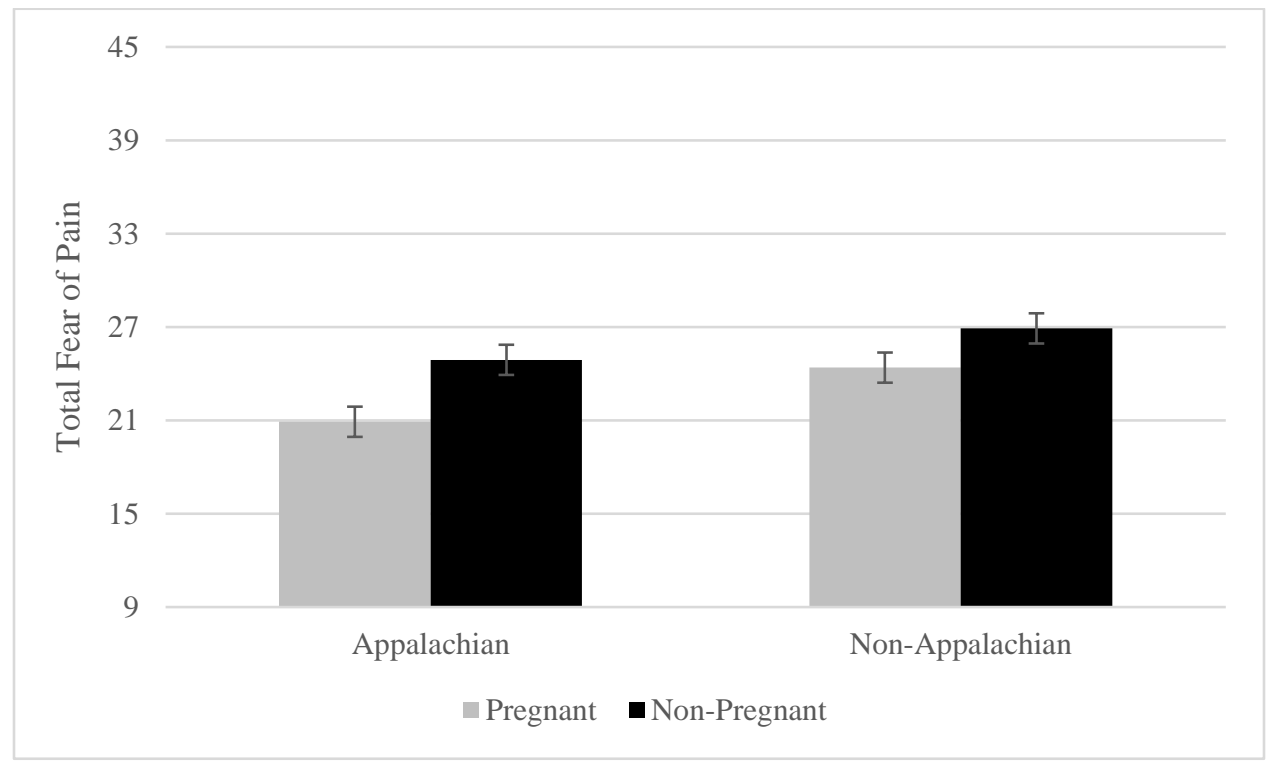

Note. $\mathrm{N}=184$. 


\section{Appendix A}

\section{Fear of Pain Questionnaire-9}

Instructions: The items listed below describe painful experiences. Please look at each item and think about how FEARFUL you are of experiencing the PAIN associated with each item. If you have never experienced the PAIN of a particular item, please answer on the basis of how

FEARFUL you expect you would be if you had such an experience. Select one number for each item below to rate your FEAR OF PAIN in relation to each event.

I FEAR the PAIN associated with:

\begin{tabular}{lccccc}
\hline & $\begin{array}{c}\text { Not at } \\
\text { all }\end{array}$ & $\begin{array}{c}\text { A } \\
\text { little }\end{array}$ & $\begin{array}{c}\text { A fair } \\
\text { amount }\end{array}$ & $\begin{array}{c}\text { Very } \\
\text { much }\end{array}$ & Extreme \\
\hline 1. Breaking your arm & 1 & 2 & 3 & 4 & 5 \\
2. Having a foot doctor remove a wart from your foot & 1 & 2 & 3 & 4 & 5 \\
with a sharp instrument & 1 & 2 & 3 & 4 & 5 \\
3. Getting a papercut on your finger & 1 & 2 & 3 & 4 & 5 \\
4. Receiving an injection in your mouth & 1 & 2 & 3 & 4 & 5 \\
5. Getting strong soap in both your eyes while & & & & & 5 \\
bathing or showering & 1 & 2 & 3 & 4 & 5 \\
6. Having someone slam a heavy car door on your & 1 & 2 & 3 & 4 & 5 \\
hand & 1 & 2 & 3 & 4 & 5 \\
7. Gulping a hot drink before it has cooled & 1 & 2 & 3 & 4 & 5 \\
8. Receiving an injection in your hip/buttocks & & & & & 5 \\
9. Falling down a flight of concrete stairs & & & & \\
\end{tabular}




\section{Demographic Questionnaire}

\section{Appendix B}

1. What is your age? (Please provide numerical answer in years)

2. What is your gender?
a. Female
b. Male
c. Other: Please specify

3. What is your height?

4. What is your weight? feet inches

5. What is your race? Select all that apply
a. American Indian or Alaska Native
b. Asian
c. Black or African American
d. Hispanic or Latino
e. Native Hawaiian or other Pacific Islander
f. White
g. Middle Eastern/North African (Non-white)
h. Other: Please specify

6. What is your marital status?
a. Single
b. Married
c. Divorced
d. Widowed
e. In a committed partnership
f. Other: Please specify

7. How many years of education have you completed? (For example, 12 years $=$ a high school diploma) years

8. What is your state of residence?

9. What is your job or occupation?

10. What is your current job or occupation status?
a. Working full-time
b. Working part-time
c. Unemployed/Looking for work
d. Retired
e. Disabled

11. What is your annual household income?
a. Less than $\$ 10,000$
b. $\$ 10,000-\$ 14,999$
c. $\$ 15,000-\$ 24,999$ 

d. $\$ 25,000-\$ 34,999$
e. $\$ 35,000$ - $\$ 49,999$
f. $\$ 50,000-\$ 74,999$
g. $\$ 75,000-\$ 99,999$
h. $\$ 100,000-\$ 149,999$
i. $\$ 150,000$ - $\$ 199,999$
j. $\$ 200,000$ or more

12. Is English your first language?
a. Yes
b. No

13. Have you ever been pregnant?
a. Yes
b. No

If yes to question 13, participants will answer the following questions:

14 . Are you currently pregnant?
a. Yes
b. No

15. If you are currently pregnant, at what stage is the pregnancy?
a. First trimester
b. Second trimester
c. Third trimester
d. I am not currently pregnant

16. If you are pregnant, who will be delivering your baby?
a. Midwife
b. Obstetrician
c. Other: Please specify

17. How many pregnancies have you had?

18. How many live births have you had?

19. How many biological children do you have?

(Number of repetitions of question 20 depends on answer to number 18) 20. What type of birth was your first birth?
a. Cesarean section
b. Medicated by epidural
c. Medicated by other medication
d. Unmedicated birth in hospital
e. Home birth

21. What type of birth was your second birth?

a. Cesarean section 
b. Medicated by epidural

c. Medicated by other medication

d. Unmedicated birth in hospital

e. Home birth

If no to question 13, participants will be brought to this question:

22. Do you presently have any pain?

$$
\begin{aligned}
& 0 \text { - no pain } \\
& 1 \\
& 2 \\
& 3 \\
& 4 \text { - severe pain }
\end{aligned}
$$

23. Right now, rate your ability to handle labor pain?

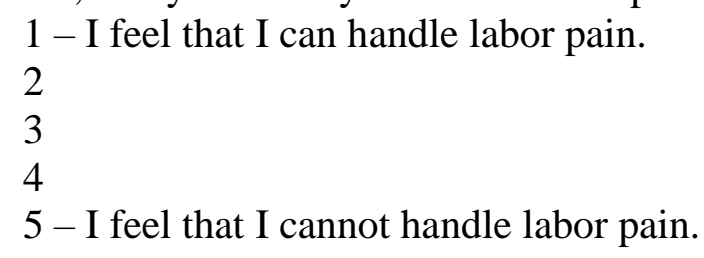

24. If you are currently pregnant, do you plan to use epidural medication during your labor?
a. Yes
b. No
c. Not applicable: Why?

25. Do you now have significant pain that has lasted 6 months or more?
a. Yes
b. No

26. If yes, how severe would you rate that pain, on a scale from $0-100$, with 0 being "no pain" and 100 being "the most pain possible"?
a. What is the source of this pain?
b. How severe would you rate that pain, on a scale from $0-100$ with 0 being "no pain" and 100 being "the maximum pain possible"?
c. How long has this pain lasted?
d. How many days a week do you experience this pain?

27. Do you now have significant pain that has lasted less than 6 months?
a. Yes
b. No

28. If yes, how severe would you rate that pain, on a scale from $0-100$, with 0 being "no pain" and 100 being "the most pain possible"?

a. What is the source of this pain?

b. How severe would you rate that pain, on a scale from $0-100$ with 0 being "no pain" and 100 being "the maximum pain possible"? 
c. How long has this pain lasted?

d. How many days a week do you experience this pain?

29. Do you currently use opioid medication to treat your pain (e.g., Oxycontin, Codeine, Oxycodone, Tylenol-3, Hydrocodone)?
a. Yes
b. No
c. Not Applicable 


\section{Appendix C}

\section{Validity Items}

Please select the number four for this question

$\begin{array}{lllll}1 & 2 & 3 & 4 & 5\end{array}$

What color are healthy teeth?

- Red

- Green

- White

- Black

What color are healthy gums?

- Blue

- Pink

- Green

- Silver

How many eyes are most people born with?

$\begin{array}{lllll}0 & 1 & 2 & 3 & 4\end{array}$

